\title{
Predicting Exchange Rates Using the Kalman Filter
}

\author{
Kateřina FRONČKOVÁ * and Pavel PRAŽÁK \\ University of Hradec Králové, Hradec Králové, Czech Republic; katerina.fronckova@uhk.cz; \\ pavel.prazak@uhk.cz \\ * Correspondence: katerina.fronckova@uhk.cz
}

\begin{abstract}
The Kalman filter is one of the classical algorithms of statistical estimation theory, which finds application in many different areas, including econometrics. One of the possible problems for which the Kalman filter can be suitably employed is the exchange rate prediction. Over the course of time, various authors have investigated the possibility of using the forward rate to predict the future spot rate. In general, however, it has been shown that the accuracy of the predictions based on the assumed equality between the forward rate and the future spot rate is not very satisfactory. The paper deals with the presentation and empirical evaluation of the possibilities of using the Kalman filter in predicting the future spot rate on the basis of the forward rate. Various models for describing the relationship between these rates are presented and their predictive performance is then assessed on the exchange rate data of currency pairs EUR/CZK and USD/CZK. The results show the benefits of using the Kalman filter.
\end{abstract}

Keywords: Kalman filter; exchange rate prediction; forward rate; spot rate

JEL Classification: $\mathrm{C} 13 ; \mathrm{C} 53$

\section{Introduction}

The relationship between the forward exchange rate and the future spot rate has been investigated by a number of authors (Engel 1996). Initially, it was assumed (Cornell 1977; Levich 1978) that the forward rate could be used as an optimal predictor for the future spot rate, i.e. that the so-called Unbiased Forward Rate Hypothesis (UFRH) holds, and the forward rate is an unbiased estimate of the future spot rate. Later, however, the views that UFRH does not hold and the forward rate is not a suitable predictor of the future spot rate began to prevail (Hansen and Hodrick 1980; Fama 1984). These views were supported by the results of many empirical studies for various currency pairs (Baillie, Lippens, and McMahon 1983; Frankel and Chinn 1993; Wesso 1999); other studies have shown that models predicting the spot rate using the forward rate do not produce better results than modeling the spot rate as a random walk (Bilson 1981; Meese and Rogoff 1983). The invalidity of the UFRH hypothesis was explained, for example, by the existence of a risk premium (Wolff 2000; Fama 1984), irrational expectations (Baillie, Lippens, and McMahon 1983) or by the influence of various external factors on the foreign exchange market (Wolff 1987). More recently, authors, in particular (Hai, Mark, and Wu 1997; Luintel and Paudyal 1998; Zivot 2000; McMillan 2005), have started to focus more closely on the cointegration relationship of the spot and forward rates, thus challenging the results of some previous studies.

(Phillips and McFarland 1997; Clarida et al. 2003) have shown that the forward rate may contain some useful information about the future spot rate. (Wolff 1987; Wesso 1999) pointed out that, according to empirical findings, the relationship between the forward rate and the future spot rate changes over time. (Wolff 1987; Barnhart and Szakmary 1991; Bonga-Bonga 2008) thus propose to construct a model with time-varying coefficients, that captures these characteristics of the relationship development and allows to achieve better predictive performance. (Wolff 2000; Bhar 2010) consider the existence of a risk premium as a time-varying unobservable variable whose inclusion in the model can explain the differences (deviations) between the forward rate and the future spot rate. The Kalman filter can be used to estimate the time-varying model coefficients and the development of the risk premium over time. 
The paper deals with the presentation and empirical evaluation of the possibilities of using the Kalman filter in predicting the future spot rate on the basis of the forward rate for currency pairs EUR/CZK and USD/CZK. Section 2 is devoted to a brief introduction of the Kalman filter and various models for describing the relationship between the spot and the forward rate. In section 3 , the results of empirical analysis are presented and discussed. Section 4 provides a final summary of the results.

\section{Methodology}

\subsection{KalmanfFilter}

The Kalman filter is a tool which enables to estimate an unknown and unobservable state of a stochastic linear dynamic system using measurements corrupted by noise. The estimate produced by the Kalman filter is statistically optimal in some sense (for example when considering the minimization of the mean square error; see (Kalman 1960) for details).

\section{Algorithm of the Kalman filter}

Let us consider a stochastic linear dynamic system in discrete time, which is represented by the following state-space model (it is assumed here that the system has no inputs)

$$
\begin{gathered}
\boldsymbol{x}_{t}=\boldsymbol{\Phi}_{t-1} \boldsymbol{x}_{t-1}+\boldsymbol{w}_{t-1}, \\
\boldsymbol{z}_{t}=\boldsymbol{H}_{t} \boldsymbol{x}_{t}+\boldsymbol{v}_{t} .
\end{gathered}
$$

Equation (1), referred to as the state equation, describes the dynamics of the system, the vector $\boldsymbol{x}_{t} \in \mathbb{R}^{n}$ is the (unknown) vector of the system state at time $t$, the matrix $\boldsymbol{\Phi}_{t-1} \in \mathbb{R}^{n \times n}$ represents the system state transition between time $t-1$ and $t$. Equation (2) is called the measurement equation, the vector $\boldsymbol{z}_{t} \in \mathbb{R}^{m}$ is referred to as the system output vector, the measurement vector or the observation vector, the matrix $\boldsymbol{H}_{t} \in \mathbb{R}^{m \times n}$ describes the relationship between the system state and the measurements. Since a stochastic system is concerned, the vectors $\boldsymbol{x}_{t}$ and $\boldsymbol{z}_{t}, t=0,1,2, \ldots$, can be considered as random variables, and their sequences $\left\{\boldsymbol{x}_{t}\right\}$ and $\left\{\mathbf{z}_{t}\right\}$ are then random (stochastic) processes.

$\left\{\boldsymbol{w}_{t}\right\}$ and $\left\{\boldsymbol{v}_{t}\right\}$ are random noise processes; these processes are assumed to be uncorrelated Gaussian processes with zero mean and covariance matrices $\boldsymbol{Q}_{t} \in \mathbb{R}^{n \times n}$ resp. $\boldsymbol{R}_{t} \in \mathbb{R}^{m \times m}$ at time $t$ (the processes have qualities of Gaussian white noise).

Furthermore, let us assume that $\boldsymbol{x}_{0}$ is a random variable having a Gaussian (normal) distribution with known mean $\boldsymbol{x}_{0}$ and known covariance matrix $\boldsymbol{P}_{0}$. Moreover, suppose that $\boldsymbol{x}_{0}$ and both the noises are always mutually uncorrelated. Thus, the following holds for all $t$

$$
\begin{gathered}
E\left\langle\boldsymbol{w}_{t}\right\rangle=\mathbf{0}, \\
E\left\langle\boldsymbol{v}_{t}\right\rangle=\mathbf{0}, \\
E\left\langle\boldsymbol{w}_{t_{1}} \boldsymbol{w}_{t_{2}}^{T}\right\rangle=\boldsymbol{Q}_{t_{1}} \delta\left(t_{2}-t_{1}\right), \\
E\left\langle\boldsymbol{v}_{t_{1}} \boldsymbol{v}_{t_{2}}^{T}\right\rangle=\boldsymbol{R}_{t_{1}} \delta\left(t_{2}-t_{1}\right), \\
E\left\langle\boldsymbol{w}_{t_{1}} \boldsymbol{v}_{t_{2}}^{T}\right\rangle=\mathbf{0}, \\
E\left\langle\boldsymbol{x}_{0} \boldsymbol{w}_{t}^{T}\right\rangle=\mathbf{0}, \\
E\left\langle\boldsymbol{x}_{0} \boldsymbol{v}_{t}^{T}\right\rangle=\mathbf{0},
\end{gathered}
$$

where the symbol $\delta$ refers to the Kronecker delta

$$
\delta(t)= \begin{cases}1, & t=0, \\ 0, & t \neq 0 .\end{cases}
$$

The aim of the Kalman filter is to produce an estimate of the state vector $\boldsymbol{x}_{t}$ at time $t$, denoted by $\widehat{\boldsymbol{x}}_{t}$, so that this estimate is optimal (for example with respect to minimizing the mean square error).

The algorithm of the Kalman filter is recursive; the calculation at time $t$ consists of two main steps. Firstly, the a priori estimate $\widehat{\boldsymbol{x}}_{t(-)}$ at time $t$ is computed through substituting the a posteriori 
estimate from time $t-1$ into the deterministic part of the state equation of the model; this step is called the prediction step. Then, this estimate is adjusted by using the measurement carried out at time $t$, which results in obtaining the a posteriori estimate $\widehat{\boldsymbol{x}}_{t(+)}$ at time $t$; this is the correction step.

The following relation can be written for the a priori estimate of the state vector $\widehat{\boldsymbol{x}}_{t(-)}$ at time $t$; the uncertainty of this estimate is expressed by the a priori error covariance matrix $\boldsymbol{P}_{t(-)}$

$$
\begin{gathered}
\hat{\boldsymbol{x}}_{t(-)}=\boldsymbol{\Phi}_{t-1} \widehat{\boldsymbol{x}}_{t-1(+)}, \\
\boldsymbol{P}_{t(-)}=\boldsymbol{\Phi}_{t-1} \boldsymbol{P}_{t-1(+)} \boldsymbol{\Phi}_{t-1}^{T}+\boldsymbol{Q}_{t-1} .
\end{gathered}
$$

Then, after obtaining the measurement $z_{t}$, the a posteriori estimate of the state vector $\widehat{\boldsymbol{x}}_{t(+)}$ is determined by the combination of the a priori estimate and the difference between the actual and the expected value of the measurement weighted by the matrix $\boldsymbol{K}_{t}$; its uncertainty is expressed by the a posteriori error covariance matrix $\boldsymbol{P}_{t(+)}$

$$
\begin{gathered}
\widehat{\boldsymbol{x}}_{t(+)}=\widehat{\boldsymbol{x}}_{t(-)}+\boldsymbol{K}_{t}\left[\boldsymbol{z}_{t}-\boldsymbol{H}_{t} \widehat{\boldsymbol{x}}_{t(-)}\right], \\
\boldsymbol{P}_{t(+)}=\boldsymbol{P}_{t(-)}-\boldsymbol{K}_{t} \boldsymbol{H}_{t} \boldsymbol{P}_{t(-)}, \\
\boldsymbol{K}_{t}=\boldsymbol{P}_{t(-)} \boldsymbol{H}_{t}^{T}\left[\boldsymbol{H}_{t} \boldsymbol{P}_{t(-)} \boldsymbol{H}_{t}^{T}+\boldsymbol{R}_{t}\right]^{-1} .
\end{gathered}
$$

A detailed derivation of the given equations of the Kalman filter can be found for example in (Grewal and Andrews 2015); more detailed presentation of the algorithm, its features and its theoretical assumptions is provided for example in (Grewal and Andrews 2015; Harvey 1989; Maybeck 1979; Simon 2006); practical aspects of the implementation of the filter are discussed for example in (Maybeck 1979; Simon 2006).

\subsection{Models of the Relationship between the Forward Rate and the Future Spot Rate}

\section{Regression model}

The relationship between the forward rate and the future spot rate can be described by a regression model

$$
s_{t+k}=\alpha+\beta f_{t}+\varepsilon_{t+k},
$$

where $s_{t+k}$ denotes the spot rate at time $t+k$ and $f_{t}$ the forward rate quoted at time $t$ with maturity at time $t+k, \varepsilon_{t+k}$ are random model residuals with zero mean. The coefficients $\alpha$ and $\beta$ can be estimated using the ordinary least squares method. The situation where $\alpha=0$ and $\beta=1$ corresponds to the validity of the UFRH; rational expectations and neutral risk are assumed.

Considering the (generally proven) exchange rate non-stationarity, it is appropriate to pay attention to testing the possible cointegration of the spot rate and the forward rate. Proving the cointegration then determines the appropriateness of using the model.

\section{Time-varying coefficient regression model}

(Wolff 1987; Barnhart and Szakmary 1991; Bonga-Bonga 2008) suggest that the coefficient $\beta$ varies over time so that the time-varying relationship between the forward rate and the future spot rate can be captured. This leads to the following model, the development of the values of the coefficient $\beta$ is modeled as a random walk (Bonga-Bonga 2008)

$$
\begin{gathered}
s_{t+k}=\alpha+\beta_{t} f_{t}+\varepsilon_{t+k}, \\
\beta_{t}=\beta_{t-1}+\epsilon_{t} .
\end{gathered}
$$

Equation (5) can be viewed as the state equation ( $\beta$ represents the estimated state variable $x$ ) and equation (4) as the measurement equation of the state-space model to which the Kalman filter can be applied as described in Section 2.1. 
(Wolff 2000; Bhar 2010) propose the idea that empirically proven deviations between the forward and the future spot rate consist of a risk premium $p$ and random deviations $\varepsilon$. They suggest the following model, risk premium development is modeled as an AR(1) process (Wolff 2000)

$$
\begin{gathered}
s_{t+k}=f_{t}+p_{t+k}+\varepsilon_{t+k}, \\
p_{t}=\phi p_{t-1}+\xi_{t} .
\end{gathered}
$$

Equation (7) represents the state equation ( $p$ is the estimated state variable $x$ ) and equation (6) represents the measurement equation, the Kalman filter can be used to solve the task of estimating the risk premium.

\section{Results and Discussion}

Data on spot and forward exchange rates for currency pairs EUR/CZK and USD/CZK were used for the empirical analysis. The data come from the website of the Czech National Bank. These are daily observations covering the period from 1 May 2001 to 31 December 2019, a total of 4,700 values (for each exchange rate). Forward rates are given in the form of forward points, which have been converted into exchange rate values for analysis purposes. Forward rates with a maturity of 3 months (90 days) and 6 months (180 days) are available. If in subsequent calculations the value of the exchange rate of a non-trading day was needed, it was replaced with the previous available value. All calculations were performed with the logarithms of the rates. Implementation was done using R.

By means of the augmented Dickey-Fuller unit root test, all the series of exchange rates were shown at the significance level of $5 \%$ to be non-stationary of type I(1). The Engle-Granger two-step method (Engle and Granger 1987) was used to assess the cointegration between the spot rate and the forward rate. For each pair of rates, coefficients of the regression model (3) were estimated by the ordinary least squares method. In all cases, the model residuals were stationary $\mathrm{I}(0)$, indicating cointegration. The relationship of cointegrated series can then be described by an error correction model, for example according to (Engle and Granger 1987) (the model is derived from the $\operatorname{ADL}(1,1)$ model)

$$
\Delta s_{t+k}=\alpha^{\prime}+\gamma^{\prime}\left(s_{t+k-1}-\beta^{\prime} f_{t-1}\right)+\delta^{\prime} \Delta f_{t}+\varepsilon_{t+k}^{\prime}
$$

The model with time-varying coefficients and the model with time-varying risk premium were estimated using the Kalman filter. At the same time, the spot rate (one-step ahead) predictions were calculated. The residuals of all constructed models (except for the basic regression) have white noise properties.

Figures 1-4 illustrate the comparison of the (logarithms of the) actual spot rate $s_{t}$ and its estimates for the currency pair EUR/CZK using the forward rate with a maturity of 3 months for the period from 1 January 2019 to 31 December 2019. Figure 1 shows estimates according to the basic regression model $\widehat{s_{t}}$, Figure 2 estimates according to the error correction model ${\widehat{s_{t}}}^{e c}$, Figure 3 estimates according to the model with time-varying coefficients ${\widehat{s_{t}}}^{t c}$, and Figure 4 estimates according to the model with timevarying risk premium ${\widehat{s_{t}}}^{r p}$. 


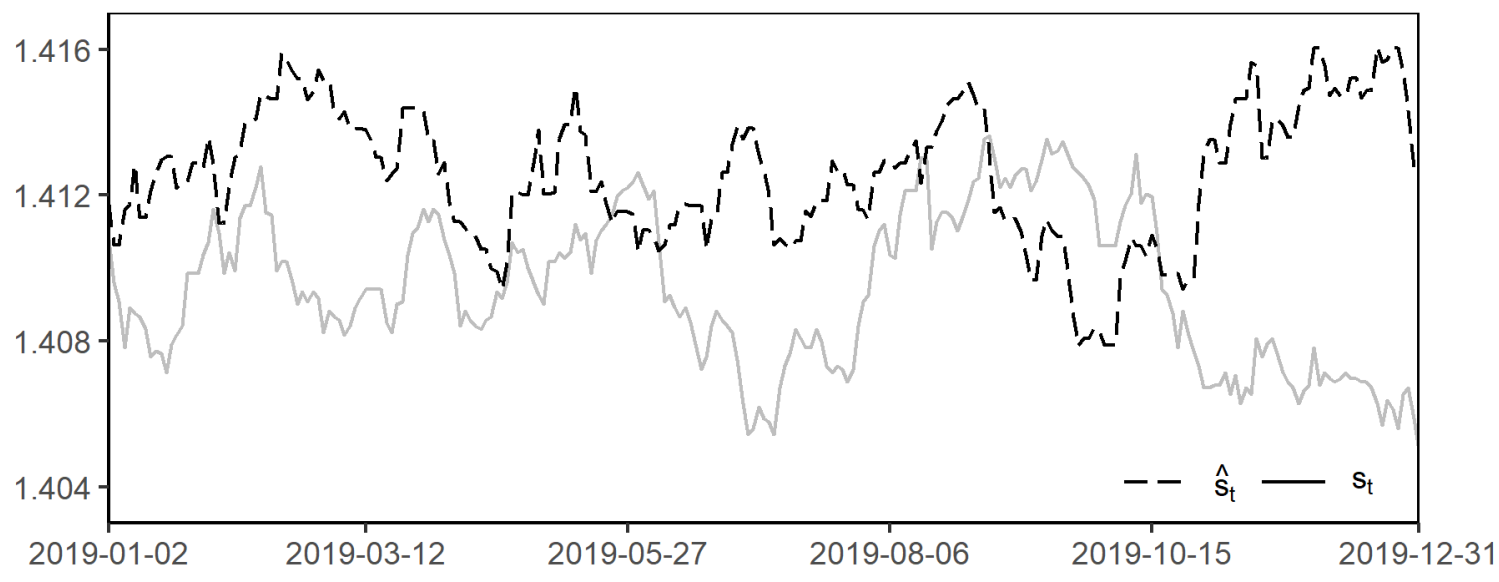

Figure 1. Spot rate and its estimates according to the basic regression model.

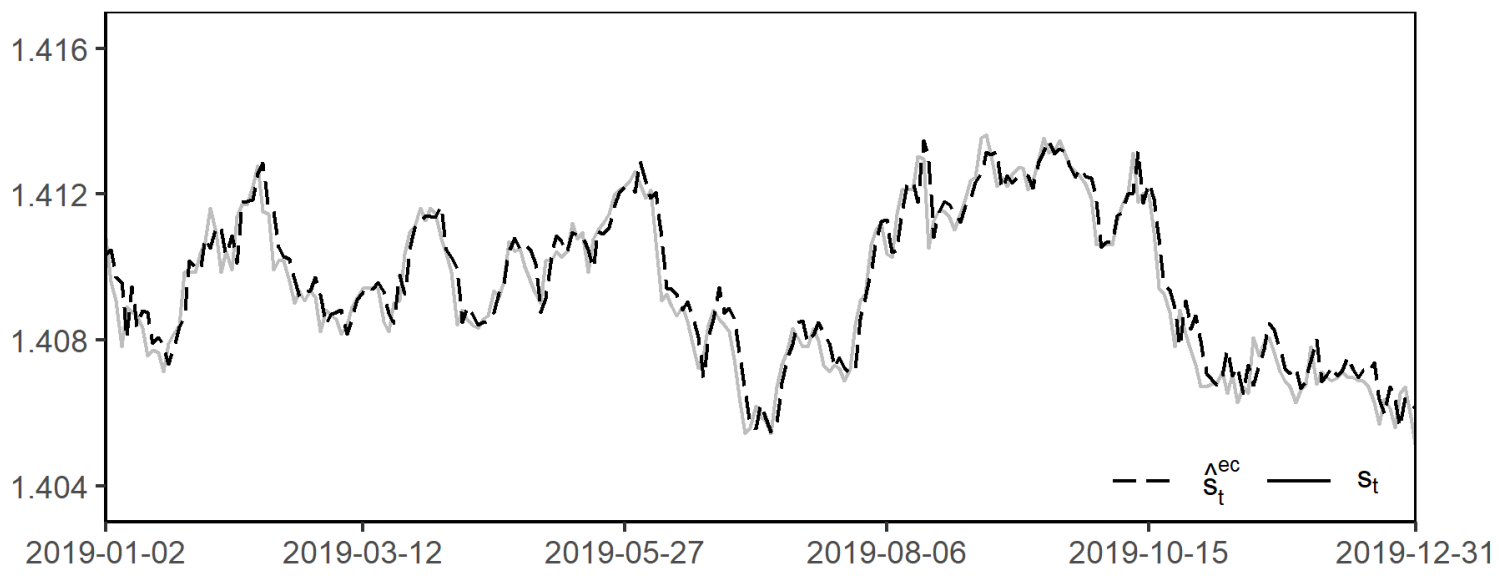

Figure 2. Spot rate and its estimates according to the error correction model.

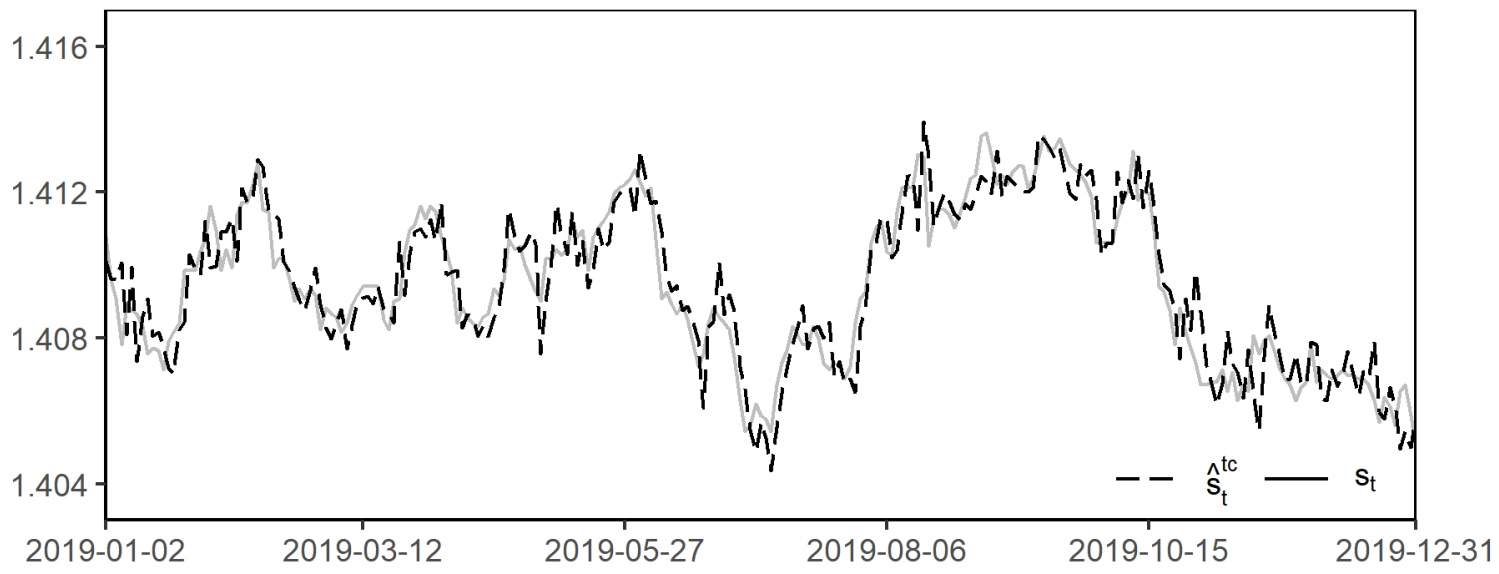

Figure 3. Spot rate and its estimates according to the model with time-varying coefficients. 


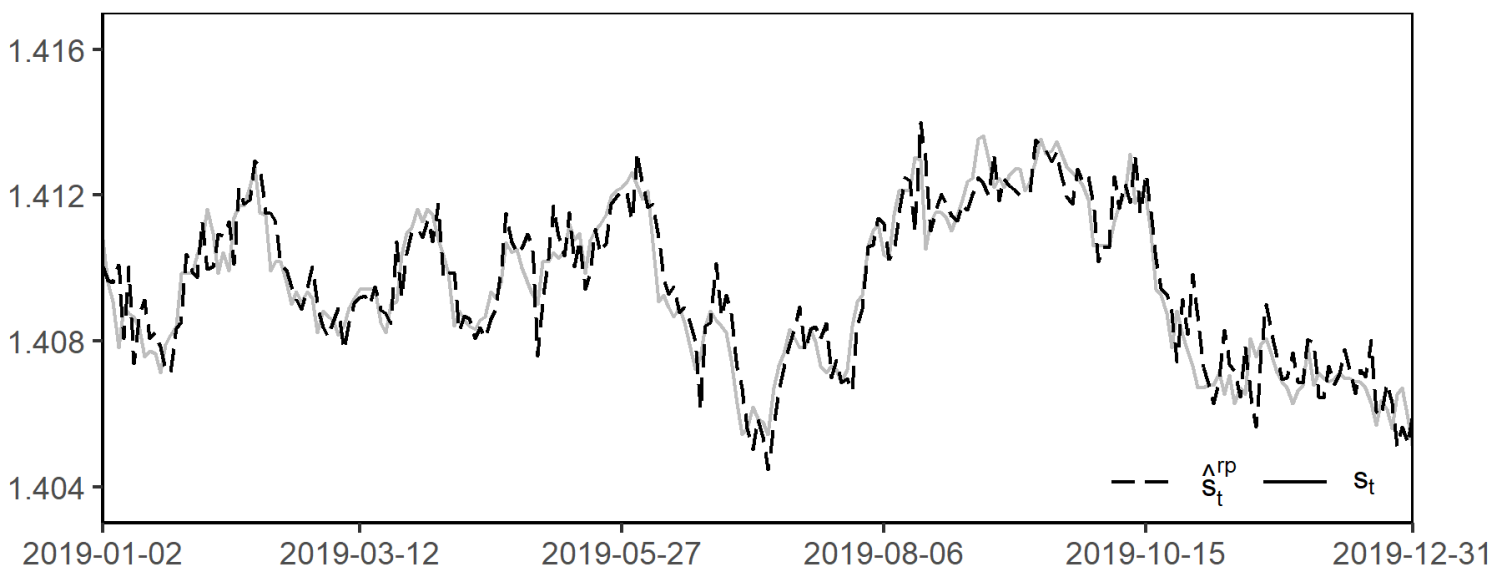

Figure 4. Spot rate and its estimates according to the model with time-varying risk premium.

The following descriptive statistics of the deviations of the predicted from the actual spot rate were calculated to assess the quality of the predictions: mean error (ME), mean absolute error (MAE), maximum absolute error (MAXAE), and root mean square error (RMSE). The results for both currency pairs and maturities of 3 and 6 months are shown in Table 1.

Table 1. Summary statistics of the predictive performance.

\begin{tabular}{|c|c|c|c|c|}
\hline & ME & MAE & MAXAE & RMSE \\
\hline \multicolumn{5}{|l|}{ EUR/CZK, 3 months } \\
\hline Basic model & $8.39 \cdot 10^{-20}$ & 0.00783 & 0.06474 & 0.01102 \\
\hline Error correction model & $-1.35 \cdot 10^{-20}$ & 0.00097 & 0.01749 & 0.00154 \\
\hline Model with time-varying coefficients & $-3.26 \cdot 10^{-20}$ & 0.00141 & 0.01895 & 0.00216 \\
\hline Model with time-varying risk premium & $-3.25 \cdot 10^{-19}$ & 0.00140 & 0.01823 & 0.00215 \\
\hline \multicolumn{5}{|l|}{ EUR/CZK, 6 months } \\
\hline Basic model & $2.06 \cdot 10^{-19}$ & 0.01096 & 0.07964 & 0.01542 \\
\hline Error correction model & $3.07 \cdot 10^{-21}$ & 0.00098 & 0.01756 & 0.00154 \\
\hline Model with time-varying coefficients & $-2.92 \cdot 10^{-20}$ & 0.00140 & 0.01790 & 0.00221 \\
\hline Model with time-varying risk premium & $-5.97 \cdot 10^{-19}$ & 0.00141 & 0.01809 & 0.00221 \\
\hline \multicolumn{5}{|l|}{ USD/CZK, 3 months } \\
\hline Basic model & $3.48 \cdot 10^{-19}$ & 0.01925 & 0.11118 & 0.02478 \\
\hline Error correction model & $-5.50 \cdot 10^{-20}$ & 0.00227 & 0.02515 & 0.00315 \\
\hline Model with time-varying coefficients & $-1.16 \cdot 10^{-19}$ & 0.00318 & 0.03744 & 0.00444 \\
\hline Model with time-varying risk premium & $-5.10 \cdot 10^{-19}$ & 0.00318 & 0.03659 & 0.00442 \\
\hline \multicolumn{5}{|l|}{ USD/CZK, 6 months } \\
\hline Basic model & $-2.82 \cdot 10^{-19}$ & 0.02647 & 0.13262 & 0.03448 \\
\hline Error correction model & $5.76 \cdot 10^{-21}$ & 0.00267 & 0.02513 & 0.00315 \\
\hline Model with time-varying coefficients & $-7.89 \cdot 10^{-20}$ & 0.00316 & 0.02859 & 0.00445 \\
\hline Model with time-varying risk premium & $-8.80 \cdot 10^{-19}$ & 0.00319 & 0.02846 & 0.00447 \\
\hline
\end{tabular}

The table shows that the basic regression model based on the assumed equality between the forward and the future spot rate achieves the worst results. As can be seen from Figure 1, in some subperiods the estimates are overvalued, in others the estimates are undervalued. The accuracy of the predictions of the model with time-varying coefficients and of the model with time-varying risk premium is very similar. The predictions constructed according to the error correction model are slightly more accurate. The mean error of all models does not significantly differ from zero; in the long term, the estimates are not systematically biased (however, in the case of the basic regression model, biases occur in partial periods, but on the whole these biases are compensated). In general, better 
results are achieved for the currency pair EUR/CZK than for USD/CZK; the maturity period has no significant impact on the accuracy of the predictions (except for the basic regression).

\section{Conclusions}

The paper dealt with the prediction of the future spot exchange rate on the basis of the forward rate and especially focused on the possibilities of using the Kalman filter in solving this task. Various models of the relationship between the spot and the forward rate were described and then their predictive performance was evaluated and compared using data on the rates of currency pairs EUR/CZK and USD/CZK. The basic model based on equality between the forward and the future spot rate cannot be considered appropriate according to the empirical results, the reason can be found in the possible invalidity of the theoretical assumptions of rational expectations and especially of neutral risk. This is the basis for other models that focus on describing the time-varying relationship of the rates. The model with time-varying coefficients, the model with time-varying risk premium, and the error correction model allow to use information on the deviations between the forward and the future spot rate and accordingly correct the basic estimates, enabling to achieve better predictive performance. The Kalman filter can be appropriately used to estimate the model coefficients and the risk premium.

Acknowledgments: The paper was supported by the Specific Research Project at the Faculty of Informatics and Management of the University of Hradec Králové, the Czech Republic.

\section{References}

Baillie Richard T., Robert E. Lippens, and Patrick C. McMahon. 1983. Testing Rational Expectations and Efficiency in the Foreign Exchange Market. Econometrica: 51, 553-563. https://doi.org/10.2307/1912145.

Barnhart Scott W., and Andrew C. Szakmary. 1991. Testing the Unbiased Forward Rate Hypothesis: Evidence on Unit Roots, Co-Integration, and Stochastic Coefficients. The Journal of Financial and Quantitative Analysis: 26, 245-267. https://doi.org/10.2307/2331268.

Bhar Ramaprasad. 2010. Stochastic Filtering with Applications in Finance. Singapore: World Scientific.

Bilson John F. O. 1981. The 'Speculative Efficiency' Hypothesis. The Journal of Business: 54, 435-451. https://doi.org/10.1086/296139.

Bonga-Bonga Lumengo. 2008. Modeling the Rand-Dollar Future Spot Rates: The Kalman Filter Approach. Working paper. No. 98 (October). Economic Research Southern Africa.

Clarida Richard H., Lucio Sarno, Mark P. Taylor, and Giorgio Valente. 2003. The Out-of-Sample Success of Term Structure Models as Exchange Rate Predictors: A Step Beyond. Journal of International Economics: 60, 61-83. https://doi.org/10.1016/S0022-1996(02)00059-4.

Cornell Bradford. 1977. Spot Rates, Forward Rates and Exchange Market Efficiency. Journal of Financial Economics: 5, 55-65. https://doi.org/10.1016/0304-405X(77)90029-0.

Czech National Bank. 2020. Foreign Exchange Market Information. Available online: https://www.cnb.cz/en/financial-markets/foreign-exchange-market (accessed on 7 January 2020).

Engel Charles. 1996. The Forward Discount Anomaly and the Risk Premium: A Survey of Recent Evidence. Journal of Empirical Finance: 3, 123-192. https://doi.org/10.1016/0927-5398(95)00016-X.

Engle Robert F., and C. W. J. Granger. 1987. Co-Integration and Error Correction: Representation, Estimation, and Testing. Econometrica: 55, 251-276. https://doi.org/10.2307/1913236.

Fama Eugene F. 1984. Forward and Spot Exchange Rates. Journal of Monetary Economics: 14, 319-338. https://doi.org/10.1016/0304-3932(84)90046-1.

Frankel Jeffrey A., and Menzie D. Chinn. 1993. Exchange Rate Expectations and the Risk Premium: Tests For A Cross Section of 17 Currencies. Review of International Economics: 1, 136-144. https://doi.org/10.1111/j.14679396.1993.tb00011.x.

Grewal Mohinder S., and Angus P. Andrews. 2015. Kalman Filtering: Theory and Practice Using MATLAB. Hoboken, NJ: Wiley.

Hai Weike, Nelson C. Mark, and Yangru Wu. 1997. Understanding Spot and Forward Exchange Rate Regressions. Journal of Applied Econometrics: 12, 715-734. https://doi.org/10.1002/(SICI)1099-1255(199711/12)12:6<715::AIDJAE470>3.0.CO;2-C. 
Hansen Lars Peter, and Robert J. Hodrick. 1980. Forward Exchange Rates as Optimal Predictors of Future Spot Rates: An Econometric Analysis. Journal of Political Economy: 88, 829-853. https://doi.org/10.1086/260910.

Harvey Andrew C. 1989. Forecasting, Structural Time Series Models, and the Kalman Filter. Cambridge: Cambridge University Press.

Kalman Rudolf E. 1960. A New Approach to Linear Filtering and Prediction Problems. Journal of Basic Engineering: 82, 35-45. https://doi.org/10.1115/1.3662552.

Levich Richard M. 1978. Further Results on the Efficiency of Markets for Foreign Exchange. In Managed ExchangeRafe Flexibility: The Recent Experience. Boston: Federal Reserve Bank of Boston.

Luintel K. B., and K. Paudyal. 1998. Common Stochastic Trends between Forward and Spot Exchange Rates. Journal of International Money and Finance: 17, 279-297. https://doi.org/10.1016/S0261-5606(98)00003-5.

Maybeck Peter S. 1979. Stochastic Models, Estimation and Control. New York: Academic Press.

McMillan David G. 2005. Cointegrating Behaviour between Spot and Forward Exchange Rates. Applied Financial Economics: 15, 1135-1144. https://doi.org/10.1080/09603100500359476.

Meese Richard A., and Kenneth Rogoff. 1983. Empirical Exchange Rate Models of the Seventies. Journal of International Economics: 14, 3-24. https://doi.org/10.1016/0022-1996(83)90017-X.

Phillips Peter C. B., and James W. McFarland. 1997. Forward Exchange Market Unbiasedness: The Case of the Australian Dollar since 1984. Journal of International Money and Finance: 16, 885-907. https://doi.org/10.1016/S0261-5606(97)00011-9.

Simon Dan. 2006. Optimal State Estimation: Kalman, H [Infinity] and Nonlinear Approaches. Hoboken, NJ: Wiley.

Wesso G. R. 1999. The Forward Rate as an Optimal Predictor of the Future Spot Rate in South Africa: An Econometric Analysis. Working paper. No. 13 (September). South African Reserve Bank.

Wolff Christian C. P. 1987. Time-Varying Parameters and the Out-of-Sample Forecasting Performance of Structural Exchange Rate Models. Journal of Business \& Economic Statistics: 5, 87-97. https://doi.org/10.1080/07350015.1987.10509563.

Wolff Christian C. P. 2000. Forward Foreign Exchange Rates and Expected Future Spot Rates. Applied Financial Economics: 10, 371-377. https://doi.org/10.1080/09603100050031499.

Zivot Eric. 2000. Cointegration and Forward and Spot Exchange Rate Regressions. Journal of International Money and Finance: 19, 785-812. https://doi.org/10.1016/S0261-5606(00)00031-0. 